\title{
Gestational diabetes mellitus, Vitamin D status and fetomaternal outcome
}

\author{
Rekha T. ${ }^{1}$, Shazia Parveen ${ }^{1 *}$, Nasreen Noor $^{1}$, Seema Hakim ${ }^{1}$, Shagufta Moin ${ }^{2}$
}

\begin{abstract}
${ }^{1}$ Department of Obstetrics and Gynecology, JNMCH, AMU, Aligarh, Uttar Pradesh, India
${ }^{2}$ Department of Biochemistry, JNMCH, AMU, Aligarh, Uttar Pradesh, India
\end{abstract}

Received: 23 April 2019

Accepted: 13 June 2019

\section{*Correspondence: \\ Dr. Shazia Parveen, \\ E-mail: shzparveen@gmail.com}

Copyright: (C) the author(s), publisher and licensee Medip Academy. This is an open-access article distributed under the terms of the Creative Commons Attribution Non-Commercial License, which permits unrestricted non-commercial use, distribution, and reproduction in any medium, provided the original work is properly cited.

\begin{abstract}
Background: Diabetes is the most common medical complication of pregnancy. Vitamin D deficiency which was initially considered only to influence bone metabolism, is now known to exert a wide spectrum of extra-skeletal effects. Vitamin D deficiency is closely associated with gestational diabetes mellitus, it also leads to adverse maternal and child outcome. Objective of this study was to compare the vitamin D levels in healthy pregnant women and women with gestational diabetes mellitus and to observe the feto-maternal outcome.

Methods: This prospective study was carried out on 160 pregnant women between the age group 20-40 years attending the Obstetrics and Gynaecology department of JNMC, AMU, Aligarh from October 2016 to October 2018. Women were divided into group A- normal pregnant women and group B- women with GDM. Estimation of vitamin $\mathrm{D}$ was done in both the groups.

Results: Mean vitamin D levels were lower in women with GDM as compared to normal pregnant women.

Conclusions: Women with vitamin D deficiency have an increased risk of developing GDM and adverse feto maternal outcome as compared to those who had normal level of vitamin.
\end{abstract}

Keywords: Fetal outcome, Gestational diabetes mellitus, Maternal outcome, Vitamin D

\section{INTRODUCTION}

Diabetes is the most common medical complication of pregnancy. Gestational diabetes mellitus is defined as carbohydrate intolerance of variable severity with onset or first recognition during pregnancy (ACOG, 2017a). ${ }^{1}$ The prevalence of GDM has been steadily increased over the past few decades. Revealed high risk factors for its occurrence are BMI $>26 \mathrm{~kg} / \mathrm{m}^{2}$, age $>25$ years, family history of diabetes mellitus, past history of GDM, history of big baby, gestational hypertension, vaginal candidiasis, premature rupture of membranes and hyperbilirubinemia in GDM mothers (Mohan et al). ${ }^{2}$ Screening should be performed between 24 and 28 weeks of gestation in those women not known to have glucose intolerance earlier in pregnancy. The diabetes in pregnancy study group India (DIPSI) criteria recommends $75 \mathrm{~g}$ oral glucose irrespective of last meal and after 2 hours venous blood glucose levels are measured. The value more than $140 \mathrm{mg} / \mathrm{dl}$ is diagnostic of GDM (Anjalakshmi). ${ }^{3}$

GDM has serious short and long term adverse health outcomes for both mothers and offspring. Although several risk factors have been identified, factors which cause GDM have not been completely elucidated. Vitamin D deficiency, which was initially considered only to influence bone metabolism, is now known to exert a wide spectrum of extra-skeletal effects, including impairment of immune system, increased risk in cardiovascular disease and hypertension, disturbances in 
neuropsychiatric function and even increased mortality (Al Alijan). ${ }^{4}$ Recent epidemiological studies have found an association between $25(\mathrm{OH}) \mathrm{D}$ levels and risk of T2DM.In vivo, vitamin D deficiency causes dysregulation of glucose metabolism by increasing insulin resistance through deteriorating $\beta$-cell function and mass (Park S, and Esteghamati A). ${ }^{5,6}$ Vitamin D induces insulin receptor expression through vitamin $\mathrm{D}$ receptor (VDR) that enhances insulin dependent glucose transport. Vitamin D deficiency was also identified as a risk factor for obesity and T2DM in women at late reproductive age (Grineva EN). ${ }^{7}$ Furthermore, in pregnant women, vitamin D deficiency leads to maternal and child infections, small for gestational age (SGA), preterm delivery, preeclampsia, GDM, as well as DNA imprinting in the infant for lifelong chronic diseases. Several observational studies about maternal vitamin D status and risk of GDM are conflicting, mostly due to differences in population characteristics such as ethnicity, geographic location, age of gestation at sampling and diagnostic criteria for GDM (Joergensen JS). ${ }^{8}$

So it is important to pay attention to vitamin D status in GDM. We aimed to investigate the effect of serum vitamin D level in the incidence of GDM along with its consequences on various biochemical parameters in pregnant women.

The aim of the present study was to evaluate and compare vitamin $\mathrm{D}$ level in healthy pregnant women with gestational diabetes mellitus. To do Glucose Screening Test $(75 \mathrm{~g}), 2$ hours in pregnant women. To evaluate vitamin $\mathrm{D}$ level in these two groups. To evaluate Maternal and fetal outcomes in the form of preeclampsia, preterm delivery, fetal growth pattern, mode of delivery, neonatal hypoglycemia and neonatal death.

\section{METHODS}

The present study was a prospective cohort study conducted on pregnant women attending OPD and IPD of OBG Department of Obstetrics and Gynecology, JNMC, AMU Aligarh from October 2016 to October 2018 after obtaining ethical approval from the institution. 160 pregnant women between the age group of 20 to 40 years were selected after obtaining informed consent. Women with anemia, multiple pregnancy, renal disease, liver disease, heart disease and type 1diabetes were excluded. Vitamin D level were estimated and correlated in normal pregnant women and in the pregnant women with GDM. Apart from basic antenatal investigations $4 \mathrm{ml}$ of venous blood was collected from each women under aseptic condition. Serum was separated by centrifuging the blood at 3000rpm for 20 minutes at 4 degree Celsius until arrayed, Estimation of 25-OH vitamin D was performed by using ELISA kit the cases were divided into two groups

- Group A- 80 normal pregnant women

- Group B- 80 women with GDM.

\section{Statistical analysis}

Chi-square test and the student " $t$ " test were applied for statistical analysis.

\section{RESULTS}

Maximum number of women in both the groups belong to the age group of 21 to 25 years, mean age was $25.55 \pm 3.04$ in group A while it was $25.7 \pm 4$ in group B. maximum number of the women belong to the urban area in both the groups. Number of illiterate women were more in group B as compared to group A and the difference between the groups was statistically significant. Numbers of unemployed women were more in both the groups. Majority of the women were multigravida in both the groups. Mean BMI of group A was $20.88 \pm 1.38 \mathrm{~kg} / \mathrm{m}^{2}$ and of group B was $25.83 \pm 1.76 \mathrm{~kg} / \mathrm{m}^{2}$, the difference was statistically significant when the groups were compared.

Table 1: Parameters in normal pregnant women and in women with gestational diabetes mellitus.

\begin{tabular}{|lll|}
\hline Parameters & Group A & Group B \\
\hline Mean age (years) & $25.55 \pm 3.04$ & $25.7 \pm 4$ \\
\hline Mean BMI $\left(\mathrm{kg} / \mathrm{m}^{2}\right)$ & $20.88 \pm 1.38$ & $25.83 \pm 1.76$ \\
\hline $\begin{array}{l}\text { Mean systolic BP } \\
(\mathrm{mmHg})\end{array}$ & $127.87 \pm 15.36$ & $131.57 \pm 16.8$ \\
\hline $\begin{array}{l}\text { Mean diastolic BP } \\
(\mathrm{mmHg})\end{array}$ & $82.78 \pm 8.43$ & $83.78 \pm 9.63$ \\
\hline Mean birth weight $(\mathrm{kg})$ & $2.9 \pm 0.49$ & $3.7 \pm 0.29$ \\
\hline Caessrean section $(\%)$ & 26.3 & 52.5 \\
\hline NICU admission $(\%)$ & 3.8 & 13.8 \\
\hline
\end{tabular}

Mean systolic blood pressure in the study group was $131.57 \pm 16.80 \mathrm{mmHg}$ and in the control group it was $127.87 \pm 15.36 \mathrm{mmHg}$. Mean diastolic blood pressure in the study group was $83.78 \pm 9.63 \mathrm{mmHg}$ and in the control group it was $82.78 \pm 8.43 \mathrm{mmHg}$. Systolic and diastolic BP in GDM women was comparatively higher than control group.

Caesarean section was done in 42 cases $(52.5 \%)$ of study group and 21 cases $(26.3 \%)$ of control group. vitamin D status play an important role in the mode of delivery by altering the smooth muscle strength and performance.

Mean birth weight was $3.7 \pm 0.29 \mathrm{~kg}$ in study group and in control group it was $2.9 \pm 0.49 \mathrm{~kg}$. NICU admission was more in study group $11(13.8 \%)$ cases as compared to the control group 3 cases $(3.8 \%)$. The reason for NICU admission was hypoglycemia (5\%), RDS (5\%), hyperbilirubinemia $(2.5 \%)$, HIE $(1 \%)$ and preterm delivery $(1.3 \%)$ (Table 1$)$.

The levels of vitamin D less than $20 \mathrm{ng} / \mathrm{ml}$ were found in 56 cases $(70 \%)$ in the study group and 7 cases $(8.8 \%)$ in the control group. Vitamin D level of $20-30 \mathrm{ng} / \mathrm{ml}$ was 
present in 18 cases $(22.5 \%)$ in the study group and 20 cases $(25 \%)$ in the control group. Vitamin D levels of more than $30 \mathrm{ng} / \mathrm{ml}$ was present in 6 cases $(7.5 \%)$ in the study group and 53 cases $(66.3 \%)$ in the control group. The difference was statistically significant when the groups were compared $(\mathrm{p}<0.01)$ (Table 2$)$.

Table 2: Vitamin D levels in normal pregnant women and in women with gestational diabetes mellitus.

\begin{tabular}{|lllll|}
\hline Vitamin D & \multicolumn{2}{l}{ Group A } & \multicolumn{2}{l|}{ Group B } \\
$(\mathbf{n g} / \mathrm{ml})$ & $\mathbf{N}$ & $\mathbf{\%}$ & $\mathbf{N}$ & $\mathbf{\%}$ \\
\hline$<20$ & 7 & 8.8 & 56 & 70 \\
\hline $20-30$ & 20 & 25 & 18 & 22.5 \\
\hline$>30$ & 53 & 66.3 & 6 & 7.5 \\
\hline Mean \pm SD & $44.50 \pm 37.01$ & \multicolumn{1}{l}{$15.63 \pm 9.50$} \\
\hline
\end{tabular}

Significance of difference $: \mathrm{t}=6.758 ; \mathrm{p}<0.001$

\section{DISCUSSION}

The results of the present study showed that $70 \%$ of the pregnant women had vitamin D level less than $20 \mathrm{ng} / \mathrm{ml}$, $22.5 \%$ had vitamin D level of $20-30 \mathrm{ng} / \mathrm{ml}$ and only $6 \%$ had vitamin D level between $20-30 \mathrm{ng} / \mathrm{ml}$. The major circulating form of vitamin $\mathrm{D}$ is $25(\mathrm{OH}) \mathrm{D}$ which is bound in plasma to vitamin D binding protein (DBP) and albumin, it is the best available marker of overall vitamin D status. Calcitriol synthesis in the kidney is regulated by parathyroid hormone. In rodent models, calcitriol has been shown to have effects on the synthesis, secretion and actions of insulin (Bourlon) leading to several human observational and interventional studies of vitamin D and type 2 diabetes mellitus, a few of which have shown a potential benefit of vitamin $\mathrm{D}$ supplementation or optimal 25(OH)D levels on type 2 diabetes (Pittas). ${ }^{9,10}$ Such studies have prompted a growing number of studies on the relationship between vitamin D status and GDM.

The increasing rates of overweight and obesity in the general population are undoubtedly contributing to the ongoing rise in the prevalence of GDM (Ferrara) which now complicates approximately $7-14 \%$ of pregnancies in the United States (Jovanoic). ${ }^{11,12}$ GDM places both mothers and their infants at risk for adverse health consequences. Women with GDM are more likely to undergo cesarean section and later develop type 2 diabetes mellitus. Infants of diabetic mothers are more likely to have congenital anomalies, macrosomia, birth trauma, respiratory distress syndrome, jaundice and hypoglycemia. While several GDM risk factors have been identified (Ben haroush) including advanced maternal age, obesity, family history of diabetes and ethnicity how these risk factors predispose women to GDM remains an active area of scientific inquiry. ${ }^{13}$ In recent years, vitamin $\mathrm{D}$ deficiency has been increasingly recognized as one potential contributor (Dror). ${ }^{14}$ While epidemiologic studies have shown a fairly consistent link between vitamin $\mathrm{D}$ deficiency and a higher risk of type 2 diabetes (Pitts) and obesity is strongly associated with both GDM (Chu SY) and vitamin D deficiency (Holick), it remains unclear whether vitamin D deficiency contributes to a mothere ${ }^{\text {ec }}$ risk of developing GDM. ${ }^{10,15,16}$

Several, but not all, observational studies have found an association between low $25(\mathrm{OH})$ D levels and increased risk of GDM. In a matched, case-control study of 54 Iranian women with GDM and 11 normoglycemic controls, Soheilykhah et al, found that maternal $25(\mathrm{OH}) \mathrm{D}$ concentrations at 24-28 weeks of gestation were significantly lower in women with GDM. ${ }^{17}$ They noted that $83 \%$ of GDM women had $25(\mathrm{OH}) \mathrm{D}$ levels less than $50 \mathrm{nmol} / \mathrm{L}$ vs. $71 \%$ of controls. Clifton-Bligh and colleague studied 264 women in Australia and found that among the $32 \%$ with GDM, 25(OH)D levels were significantly lower compared to normoglycemic women. ${ }^{18}$ In another study of Iranian women at high risk for vitamin D deficiency, Hossein-Nezhad and colleagues found that $29 \%$ of 741 women had $25(\mathrm{OH}) \mathrm{D}$ levels less than $15 \mathrm{nmol} / \mathrm{L}$ and the prevalence of GDM in this subgroup was higher compared to women with $25(\mathrm{OH}) \mathrm{D}$ levels more than $35 \mathrm{nmol} / \mathrm{L} .{ }^{19}$ Likewise, Zhang et al found in a nested case-control study in the United States (Washington) of 57 cases of GDM, that maternal $25(\mathrm{OH}) \mathrm{D}$ levels at 16 weeks $^{\text {ee }}$ gestation were $20 \%$ lower among women who later developed GDM. ${ }^{20}$

\section{CONCLUSION}

The present study provides valuable insight towards the definition of gestational diabetes mellitus (GDM) and normal levels of vitamin D and effect of vitamin D deficiency on pregnant women and fetus. Our assessment of GDM status and serum vitamin D levels in pregnant women of North India, a population known to suffer from high incidence of both GDM and vitamin D deficiency, suggests an increased risk of development of GDM in women who are deficient for vitamin D when compared to their non GDM counterparts. The study revealed a significant correlation between GDM, vitamin D and BMI. Overall limitation of the present study is small sample size and vitamin D supplementation has been not done to define the role of vitamin D in glycemic status of GDM and on maternal and fetal outcome. So, further studies with bigger sample size involving vitamin D supplementation are needed to define the role of vitamin D in GDM.

Funding: No funding sources Conflict of interest: None declared

Ethical approval: The study was approved by the Institutional Ethics Committee

\section{REFERENCES}

1. American College of Obstetricians and Gynecologists: Gestational diabetes mellitus. Practice Bulletin No. 180; 2017.

2. Mohan MA, Chandrakumar A. Evaluation of prevalence and risk factors of gestational diabetes in 
a tertiary care hospital in Kerala. Diabetes Metab Syndr. 2016;10:68-71.

3. Anjalakshi C, Balaji V, Balaji MS. Single test procedure to diagnose gestational diabetes mellitus, Acta Diabetol. 2009;46:51.

4. Abdulrahman Al-Ajlan, Sara Al-Musharaf. Lower vitamin D levels in Saudi pregnant women are associated with higher risk of developing. GDM BMC Pregnancy and Childbirth. 2018:18.

5. Park S, Kim da S, Kang S. Vitamin D deficiency impairs glucose- stimulated insulin secretion and increases insulin resistance by reducing PPARgamma expression in nonobese type 2 diabetic rats. J Nutr Biochem. 2016;27:257-65.

6. Esteghamati A, Aryan Z, Nakhjavani M. Vitamin D deficiency is associated with insulin resistance in nondiabetics and reduced insulin production in type 2 diabetics. Horm Metab Res. 2015;47(4):273-9.

7. Grineva EN, Karonova T, Micheeva E, Belyaeva O, Nikitina IL. Vitamin D deficiency is a risk factor for obesity and diabetes type 2 in women at late reproductive age. Aging (Albany NY). 2013;5(7):575-81.

8. Joergensen JS, Lamont RF, Torloni MR. Vitamin D and gestational diabetes: an update. Curr Opin Clin Nutr Metab Care. 2014;17(4):360-7.

9. Bourlon PM, Billaudel B, Faure-Dussert A. Influence of vitamin D3 deficiency and 1,25 dihydroxyvitamin D3 on de novo insulin biosynthesis in the islets of the rat endocrine pancreas. J Endocrinol. 1999;160:87-95.

10. Pittas AG, Lau J, Hu FB. The role of vitamin D and calcium in type 2 diabetes. A systematic review and meta-analysis. J Clin Endocrinol Metab. 2007;92:2017-29.

11. Ferrara A, Kahn HS, Quesenberry CP. An increase in the incidence of gestational diabetes mellitus:
Northern California, 1991-2000. Obstet Gynecol. 2004;103:526-33.

12. Jovanovic L, Pettitt DJ. Gestational diabetes mellitus. JAMA. 2001;286:2516-8.

13. Ben-Haroush A, Yogev Y, Hod M. Epidemiology of gestational diabetes mellitus and its association with Type 2 diabetes. Diabet Med. 2004;21:103-13.

14. Dror DK. Vitamin D status during pregnancy: maternal, fetal, and postnatal outcomes. Curr Opin Obstet Gynecol. 2011;23:422-6.

15. Chu SY, Callaghan WM, Kim SY. Maternal obesity and risk of gestational diabetes mellitus. Diabetes Care. 2007;30:2070-6.

16. Holick MF. Vitamin D deficiency. N Engl J Med. 2007;357:266-81.

17. Soheilykhah S, Mojibian M, Rashidi M. Maternal vitamin D status in gestational diabetes mellitus. Nutr Clin Pract. 2010;25:524-7.

18. Clifton-Bligh RJ, McElduff P, McElduff A. Maternal vitamin D deficiency, ethnicity and gestational diabetes. Diabet Med. 2008;25:678-84.

19. Hossein-Nezhad A, Maghbooli Z, Vassigh AR. Prevalence of gestational diabetes mellitus and pregnancy outcomes in Iranian women. Taiwan J Obstet Gynecol. 2007;46:236-41.

20. Zhang C, Qiu C, Hu FB, David RM, van Dam RM, Bralley A, et al. Maternal plasma 25-hydroxyvitamin $\mathrm{D}$ concentrations and the risk for gestational diabetes mellitus. PloS one. 2008;3(11):e3753.

Cite this article as: Rekha T, Parveen S, Noor N, Hakim S, Moin S. Gestational diabetes mellitus, Vitamin D status and fetomaternal outcome. Int J Reprod Contracept Obstet Gynecol 2019;8:3300-3. 